\title{
Global Sounds and Local Sentiments: A Survey of Improvised Music in Contemporary China
}

\section{Jing Wang}

\section{Introduction}

On a Sunday afternoon in September 2014, inside of JZ Club in the city of Hangzhou, about twenty people were listening to a free live collective improvisation music show. To avoid conflict with normal business hours, the venue owner suggested that the show begin at 3pm, making it accessible only for those who were interested in the music, not those seeking to socialize and drink. The show consisted of the Swiss trio Deer-Hans Koch, Christian Müller, and Silber Ingold playing bass clarinet and electronic devices and effects-collaborating with two Chinese musicians: Wang Changcun from Hangzhou on laptop and Zhao Junyuan (also known as Jun-Y Chao) from Shanghai on clarinet and snare drum. The ensemble created a dark, growling, and hypnotic soundscape, transforming three floors into a resonating conch shell.

\begin{abstract}
A few months before the show, Deer had contacted me saying that they were planning a music tour in China and wanted to play in Hangzhou with local musicians. I agreed to organize a concert immediately, but it took several months to find two musicians who were able and willing to improvise. Most of the musicians I approached (both academics and professionals) were interested but not confident enough to improvise. The only name that was frequently recommended to me was Li Jianhong, who had moved to Beijing two years earlier and was already scheduled to play with Deer in Beijing. Finally, Wang Changcun, a laptop experimental musician who played in almost every music event I arranged in Hangzhou, agreed to join the group. Two weeks before the scheduled show time, Zhao Junyuan, a dear friend of mine from Shanghai, called and said that he would accept my invitation to play with Deer. Junyuan had trained as a visual artist and musician at the Academy of Fine Arts in Düsseldorf, Germany.
\end{abstract}

The difficulty in finding musicians to participate in collective improvisation shows how scarce this practice is in Hangzhou. Beijing and Shanghai might have more options, but the number of improvising musicians in each city is still no more than five or six. The aim of this essay is to introduce the most active improvising practitioners in major Chinese cities such as Beijing, Shanghai, Guangzhou, and Shenzhen to the free improvisation communities of North America. China's contemporary improvising practices foster a kind of atmospheric relation among musicians, audience, and the environment. Importantly, the environment is not simply the site where improvisation occurs, but an important constitutive element in an improvising event. Different environments trigger and affect the dynamic of the improvising practice; the improvising practice affects and transforms the environment in the process of improvising and listening. This context specific aspect of China is what makes its improvising practice so unique and significant.

\section{Descriptions}

Each major Chinese city has a unique socio-cultural atmosphere that affects the practice, performance, and reception of alternative music. Beijing is often known as the rock and roll city, Shanghai the jazz city, and Guangzhou and Shenzhen the cities of Cantopop. ${ }^{1}$ These cities are also where one finds the most active improvising, experimental, and electro-acoustic music scenes in contemporary China. Improvised music (except for jazz) is not taught in music academies in China. Most active improvising musicians are autodidacts, learning from the Internet, radio shows, magazines, and CDs brought from abroad by traveling musicians.

\section{Improvised Music in Ancient China: Guqin}

There exists a history of improvised music in ancient China, which is associated with the practice of guqin (a sevenstring instrument similar to the zither). Despite a fracture in guqin practices in modern Chinese history, the sustained spiritual and aesthetic connection between guqin and China's improvised music traditions is important to understand.

The guqin was popular among scholars in early medieval China from the end of the Han Dynasty to the beginning of the Tang Dynasties (c. 200-619 A.D.). Discussions of the aesthetics of the guqin and its practice reached their heyday in the Tang Dynasty, when improvisation became a focus (see Li and Yang). Yang uses the word luan (chaotic or random) to describe the improvisation section of certain guqin pieces:

The chaotic part at the end of the notation of Guanglinsan is a collective creation through history. Every performer added to the notation their own interpretations and tastes . . Judging from several recordings of this piece in modern times, none of those known Guqin players did a good job in playing the last part. They 
all sounded burdensome. The problem is that they did not go beyond the notation. The only way to play 'chaotic sound' is to abandon the original notation, to improvise. (my trans.; 87)

The practice of guqin emphasizes performers' "recreation" abilities. In ancient times, when there was no notation, musicians learned melody by listening to performance and recreating and reinterpreting the piece. Listening and the ability to interpret melody was important for guqin players. Even in modern times, where standardized notation exists for most instruments, the notations for Guqin melodies, according to Liang Mingyue, are only a "blueprint for the performers," and "the fingering symbols come to life only through the performer's understanding and sensibility" $(200)^{2}$

Despite the guqin's popularity and high social status in Chinese classical culture, it remains a lesser known and studied instrument, partly because of the difficulty involved in mastering it, but perhaps more due to the banning of the scholarly class ${ }^{3}$ during the Cultural Revolution (1966-76): considered a symbol of feudalism, this class was one of the primary targets for re-education under the aim of overcoming the difference between mental and manual labour. The burning of the books and property of the scholarly class was secretly described by a Chinese proverb: "burning the guqin, cooking the white crane."4 (In Chinese mythology, the guqin is a symbol of intelligence and wisdom and the white crane a symbol of immortality). In recent years, the guqin has enjoyed a revival among intellectuals and other educated or wealthy individuals, and its aesthetics and practice have reappeared in new Chinese music scenes. For example, the guqin player Wuna often improvises with China's experimental musicians, such as the duo FM3 (Zhang Jian from Beijing and Nebraska native Christiaan Virant), Yan Jun, and Douwei.

Of course, not everyone holds a positive view of the guqin's role in contemporary Chinese music. Guqin player Yang Dian, for instance, reflecting on his collaboration with Dou Wei (bass) and Zhang Jian (laptop) on the recording Z: Zorro in China (2007), criticized Wei and his group Buyiding (which translates in English as "uncertainty") for their lack of structure: "although it is improvised music, it is too ambiguous, provisional, and random" (my trans.; 164). For him, the guqin is too often used as decoration and practiced superficially in the improvised and experimental music scene.

\section{C.F.I. Record Label}

While some independent music labels (Kwanyin, We Play!, Post Concrete) occasionally release improvised music, there is one label founded by Li Jianhong in 2011_China Free Improvisation (C.F.I.) - that focuses solely on this genre. Li Jianhong designed C.F.I. to be a platform for the development of free improvised music, and its website lists many of the primary free improvisers of mainland China: Li Zenghui (saxophone), Feng Hao (guitar), Li Weisi (guitar), Yan Jun (feedback system), Yan Yulong (violin), Sheng Jie (violin), Weiwei (laptop), Liu Xinyu (guitar), Wang Ziheng (saxophone), A Ming (cello), Zhu Wenbo (clarinet), Maimai (guitar), Jun-Y Chao (clarinet and saxophone), Li Yangyang (guitar and voice), and Li Jianhong (guitar), as well as the groups Mind Fiber (Li Jianhong and Weiwei), Soviet Pop (Li Qing and Li Weisi), and MTDM (Jun-Y Chao and Taoyi).

Every one of these musicians is known for practicing more than one genre of music, including world, electroacoustic, and rock. In fact, Western categories of free improvisation, free jazz, experimental, noise, and sound art are mixed and used rather loosely in China. While some musicians develop their own improvisatory aesthetics from Chinese philosophies associated with guqin, others incorporate many different foreign influences into their musical thinking and practice, including the work of composers like John Cage and Morton Feldman, playwrights like Samuel Beckett and Antonin Artaud, and art movements such as happenings and the Fluxus movement.

\section{Improvisation within the Environment: Li Jianhong, Frog Jam, and the Tea Rockers Quintet}

As the founder of C.F.I. and also the organizer of the 2pi festival (to be discussed later), Li Jianhong is a highly respected figure in China's experimental and free improvising music scene. Li began to develop the idea of environment improvisations in 2004 after experiencing an epiphany during a mountain walk to Faxi Temple in Hangzhou:

The smoke from the burning incense in front of Mahavira Palace was not psychedelic, but when it met and mixed with the rain vapor, it started some visual and aural chemical actions. I heard the chanting sounds from inside of the palace covering the entire temple and mountains. I could not feel the contour of my ears. It became everywhere-suspended above the mountains and the temple wrapped by the rain and chanting sounds. The ear listened with joy and ease. Facing the scene, I thought the best thing to do is to sleep. In fact, I did not consider there was a choice. I fell asleep. I know it was in fact very normal to encounter such a rain in the mountain. The rain, originally that of the universe, became my rain, because I existed that day. After that, I had a thought to make music with rain . . (qtd. in Wang, "Affective Listening") 5 
In 2011, at a workshop held at the Art Institute of Chicago, Li hesitated to use the term "dialogue" to describe the relationship between improviser and environment: "in environment improvisation, I am not in an equal relation with environmental sounds, and there is no one-on-one dialogue between me and the nature ... environment coexists with my playing as one" (qtd. in Wang, "Affective Listening"). Li later used the term "friction" to describe what happens both conceptually and physically between the improviser and the environment.

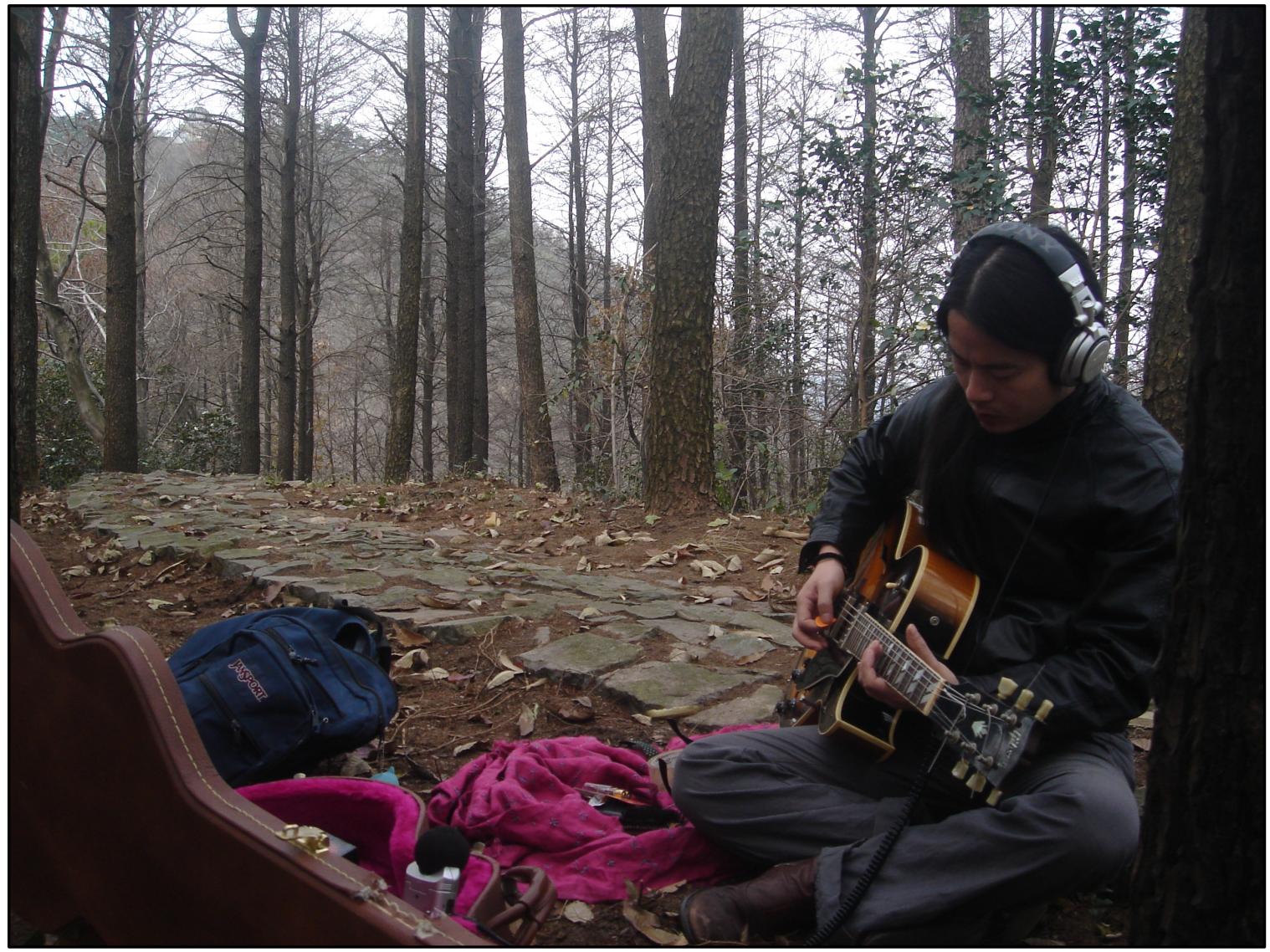

Fig. 1. Li Jianhong practicing free improvisation. Hangzhou, China. Photo courtesy of Li Jianhong.

Interestingly, Li emphasizes that in environment improvisation, there is no audience: only the improviser and the ambient environment. This idea goes against what we normally consider improvisation, which usually includes a participating audience: "free improvising does not play for a body of audience; instead, it is a very private and intimate event." For example, in one recording Li made at his parents' home in Fenghua village in Zhejiang province, we hear guitar sounds mixed with occasional conversations: Li's mother calls from downstairs, "the meal is ready," while he is recording, and he responds, "yes, I am coming," while playing his guitar, a pattern that repeats a few minutes later. This is what Li means when he refers to environment improvisation as a private event, one that here incorporates the intimate relationship between his mother and him.

What is the "environment" in environment improvisation? First, it refers to both natural and everyday living environments. Li suggests that there is no environment during free improvisation, only a subjective projection of the improviser. In the process of improvising, the improviser responds to a self in constant change. The entire process is fragile and not to be observed. Thus, as Li suggests, it is always an adventure to improvise freely in a public space, but it is also necessary for musicians to incorporate the audience and other external influences into their own personal, spiritual, embodied environments: "environment improvisation is not responsible for anyone. The only thing an improviser has to be responsible for is his/her feelings and sensations . . . those who are affected by environment improvisation are those who hear oneself." 


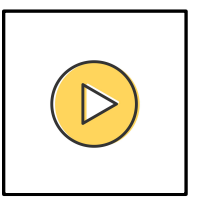

Click the icon above to listen to "Twelve Situations" by Li Jianhong [Adobe software may be required to view content].

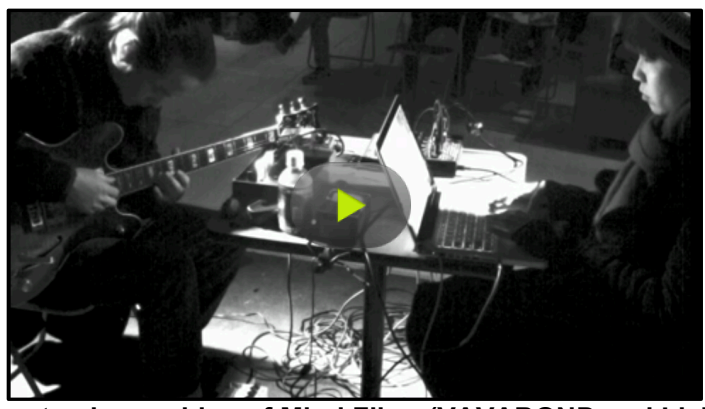

Click the image above to view a video of Mind Fiber (VAVABOND and Li Jianhong) live at XP.

Li's aesthetic conception of environment improvisation evokes the guqin, an instrument, as discussed earlier, traditionally played mostly by scholars in ancient imperial China who excelled in music, painting, and poetry. This connection is exemplified by Frog Jam, an experimental music project initiated in Shenzhen by guqin player Shen Piji that brings traditional instruments such as the guqin and the shakuhachi (a traditional Japanese bamboo flute introduced from China in the $8^{\text {th }}$ century and first played by Zen Buddhist monks) together with electronic laptop music. Piji performs in his front yard using five different shapes of ceramic containers in his front yard and a group of hylarana daunchina (a "music frog" endemic to China) that he has raised. When the music starts, these frogs jump into the containers and make sounds with different pitches, volume, and intensity that the musicians improvise around. According to Piji, the guqin is not used to entertain an audience; it is played in a natural environment for those who truly understand its music.

Another improvising collective, The Tea Rockers Quintet, also combines traditional instruments such as the guqin and pipa (a four-stringed instrument often referred to as the Chinese lute) with contemporary electronic instruments. The Tea Rockers Quintet includes Yan Jun (feedback system), Wu Na (guqin), Xiaohe (guitar, voice, laptop), Li Daiguo (voice and multi-instrumentals), and a non-musical tea ceremony performed by Lao Gu. The group was formed in Berlin in 2010 when these five artists performed at the same music festival. They describe The Tea Rockers Quintet as "a twist folk-world music band that sometimes laugh at themselves on stage." The kind of tea they drink during the concert defines the state of their performance. ${ }^{6}$ On their album Ceremony, one can sometimes hear the clicking of teacups. This group embodies the self-entertaining and self-cultivating spirit of popular free improvisation in China, which is also inherent in environment improvisation. The major difference is that $\mathrm{Li}$ emphasizes non-dialogic relation in environment improvisation, while the Tea Rockers Quintet tends to develop a collective dialogue in process improvising.

\section{Mafeisan and Free Improvising Noise Music}

Mafeisan, another improvising collective founded in Beijing in 2005, also focuses on "the self," but differs from the previous groups in that its members live together as a community rather than leading separate lives outside of their musical collaborations. On the C.F.I. website, Mafeisan is described as "the best Chinese noise experimental group," and its members include Li Yangyang, Zhang Zhongshu, and Liu Siyuan (all of whom also belong to an underground music community called Raying Temple, founded by Mafeisan and other Beijing-based improvisers).

Raying Temple is also the name of an underground venue first opened in 2003 that hosts travelling musicians from the global free improvisation and experimental music scenes, including Staalplaat Soundsystem from Amsterdam, Australian noise artist Justice Yeldham, guitarist Makoto Kawabata (founding member of Acid Mothers Temple) and drummer Yoshida Tatsuya from Japan, and the saxophone collective Ryoko Ono (Otomo Yoshihide from Japan, Ryu Hankil from South Korea, and Sin:Ned from Hong Kong). 


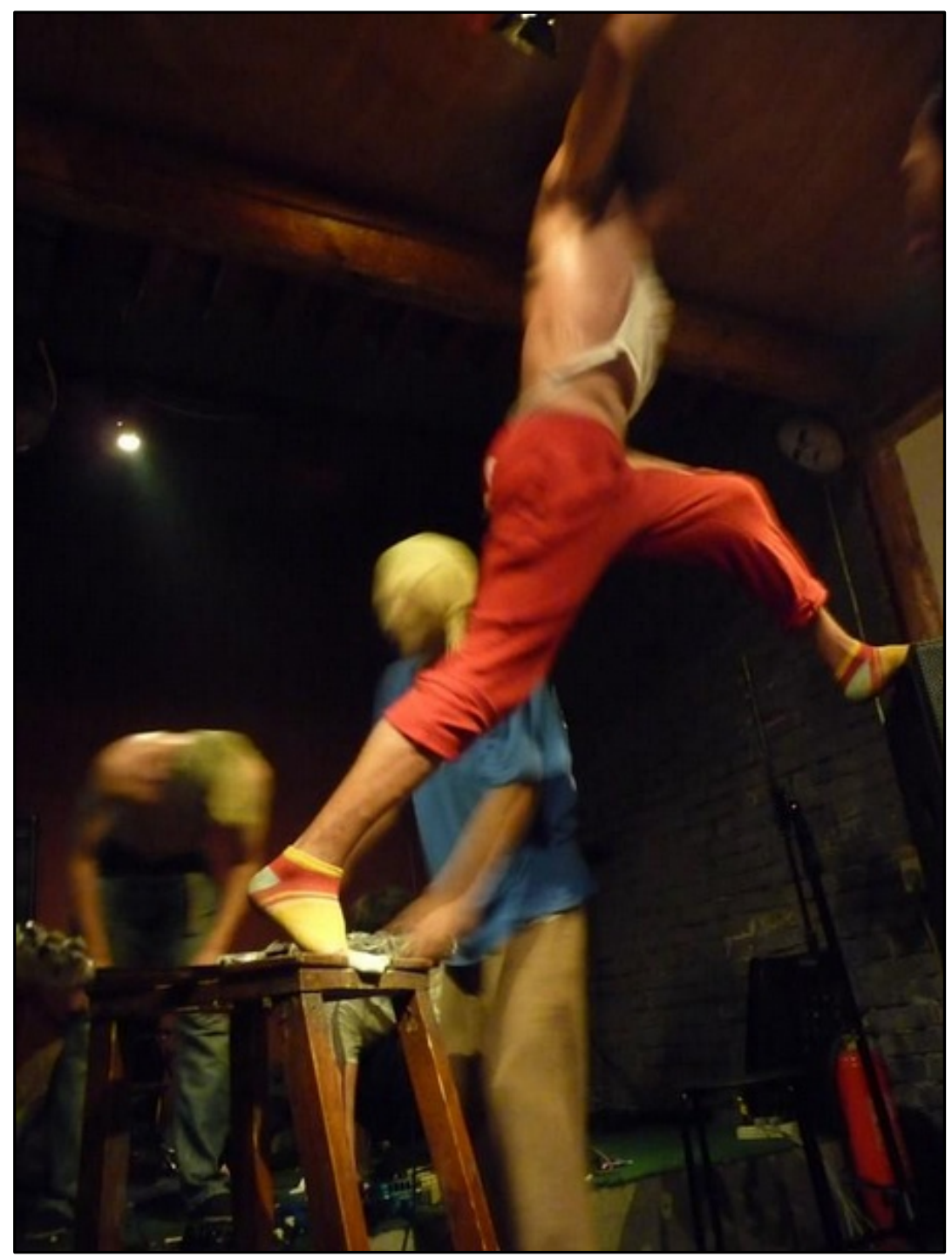

Fig. 2. Mafeisan in performance. Photo courtesy of Mafeisan.

In my article "Utopian Impulses," I discuss in detail the Raying Temple venue and Mafeisan's communal life and musical practice. In contrast to Li Jianhong, the members of Mafeisan do not talk much about their music. They use Buddhist and mythical vocabulary to describe their improvisational practices: a tool for reaching and expressing one's innermost self in order to actualize a utopian state. The rejection in free improvisation of structure and melody is particularly appealing to those looking for an instinctual—or "authentic"—form of musical expression. Improvising noise is thus for Mafeisan not only a musical style, but also a lifestyle.

Limited by its budget, Raying Temple has relocated four times mainly due to leasing issues and has been renovated (at different rented spaces) with items found either in recycling stations or through the black market. It burned down in 2008 and was finally closed in 2012, evolving into a nomadic virtual space. Thus for the organizers of Raying Temple, nothingness (xuwu in Buddhism) and true self (an authentic self not affected by the outside world) have become extra-musical connotations of free improvisation.

In September 2012, a few months after Raying Temple lost its space in Tongzhou, Mei Zhiyong and Mafeisan from Raying Temple, Shanghai-based noise group Torturing Nurse, and Sin:Ned from Ryoko Ono went to Japan at the invitation of Shayne Bowden to perform at the Against 2012 extreme music festival in Fukuoka. They videotaped their performances in different venues on this tour and shared them on their websites. Mafeisan's performance on September 6, 2012 at Earthdom in Tokyo exemplifies their approach. The show begins with Zhang Zhongshu and Liu Siyuan operating mixers and effects, creating a chaotic and extreme noise-scape mixed with earsplitting, high frequency sound. Yangyang joins a few seconds later, playing his guitar while constantly moving around on the stage, sometimes standing close to Zhongshu and Siyuan, sometimes moving away from the two while turning his 
back towards the audience. He unpredictably jumps over wires and effects on the floor and plays while standing at the very edge of the stage. Throughout the show, Zhongshu and Siyuan play with their heads bent over their mixers, their long hair completely covering their faces. Yangyang is much more performative. Most of the time, he bounces violently back and forth, holding his guitar toward the Marshall amp for feedback effects. He also kneels down and occasionally shakes his guitar like a machine gun. The show lasts ten minutes, ending with Yangyang creating low roaring sounds through the microphone.

\section{Global and Local Influences}

\section{Rock Music in Post-Tiananmen China}

China's current improvised and experimental music practices evolved in the 1990s when, in spite of the failure of the 1989 student protests at Tiananmen Square, China's rock music split into popular rock managed by the music industry and an underground rock culture focused on new and innovative musical expression (Baranovitch 36).

Yan Jun, one of the most important improvisers and sound artists in China, exclaimed once to me that China's sociocultural spirit in the post-Tiananmen era is best captured by noise: "after the June 4th incident, there is no music in China, only noise. The state-owned media creates 'CCTV Spring Festival Gala' and 'CCTV One Song' to comfort the pubic, to demonstrate that we are still a big community, living together. But in fact, we are not. We are separated by that event. We can no longer get together."

Although it often seems that the June 4th incident and the Chinese government's subsequent "reform and openingup" policy ended the 1980s age of idealism, in this emerging underground music culture one could still feel a yearning for free expression. Underground musicians believed that to remain independent and self-aware, they must eschew the soothing tones, the ideological clichés, that catered only to the aesthetic sensibilities of the ruling party. Thus they sought out more innovative paradigms, including industrial noise, punk, extreme metal, and avant-garde electronica.

Even though a few live experimental music shows were performed in the 1990s by foreign musicians in mainland China, the majority of rock fans and musicians were not ready to accept these new practices: thus musical and commercial resources for these experimental genres were rather limited. For example, in early 1993 the experimental Japanese musician Otomo Yoshihide and the Australian jazz violinist Jon Rose were invited to the Beijing International Jazz Festival. This was the earliest live experimental music performance in Mainland China, and little of it was recorded or documented. In 1995, with the help of independent artist and curator Ou Ning, Hong Kong musician Dickson Dee (Li Chin Sung) toured the cities of Shenzhen, Foshan, and Beijing with American avant-garde musician John Zorn and Japanese noise musician Yamantaka Eye. Again, there is no record of this tour, and little is known about how it was received by audiences. ${ }^{7}$ As an organizer with his own independent music labels (Sound Factory, Sonic Factory, Noise Asia), Dickson Dee was able to introduce new trends in experimental music and free improvisation to mainland China, but his influence did not reach far.

These examples reinforce the fact that to develop further, underground music culture needs not only new practices, but also a robust cultural and philosophical backbone. The magazine Free Music, despite a life of less than a year, played a critical role in shaping this backbone (see Fig. 3).

When first released in October 1999, Free Music was considered by music critics and fans as the most radical and courageous magazine on the mainland. Its editor, Yang Bo, ${ }^{8}$ intended in an open letter to readers to present "the most critical words, the most sincere emotions, and the most cutting-edge rock music" (my trans.). The manifesto Yang coined for Free Music's first volume_-music is only a means, freedom is the purpose"-immediately resonated within underground music circles and generated fierce discussion about the relationship between musical expression and intellectual freedom. For most readers, this magazine was about not just rock music, but also its social, cultural, and philosophical implications. There were introductions to controversial foreign musicians, discussions about sexual repression, and interviews with underground celebrities.

Yang also corresponded with readers who were feeling angry and lost. One reader wrote that he should take away pictures that might be considered pornographic by the state so that the magazine could continue to be released. The advice, however, came too late. Soon after the third issue, Free Music was deemed "extremely unhealthy" and prohibited by the State Ministry of Culture. ${ }^{9}$ Yang reproduced the letter (see Fig. 4) in the magazine's subsequent, unreleased fourth issue, of which twenty copies were said to have been printed in 2000 .

Free Music was the only magazine of its time to introduce cutting-edge music such as German experimental electronica, European industrial rock, and extreme metal to Chinese audiences: with only three released issues and 
one uncirculated, it was nevertheless regarded as "the second enlightenment" by China's underground music culture (FBJ).

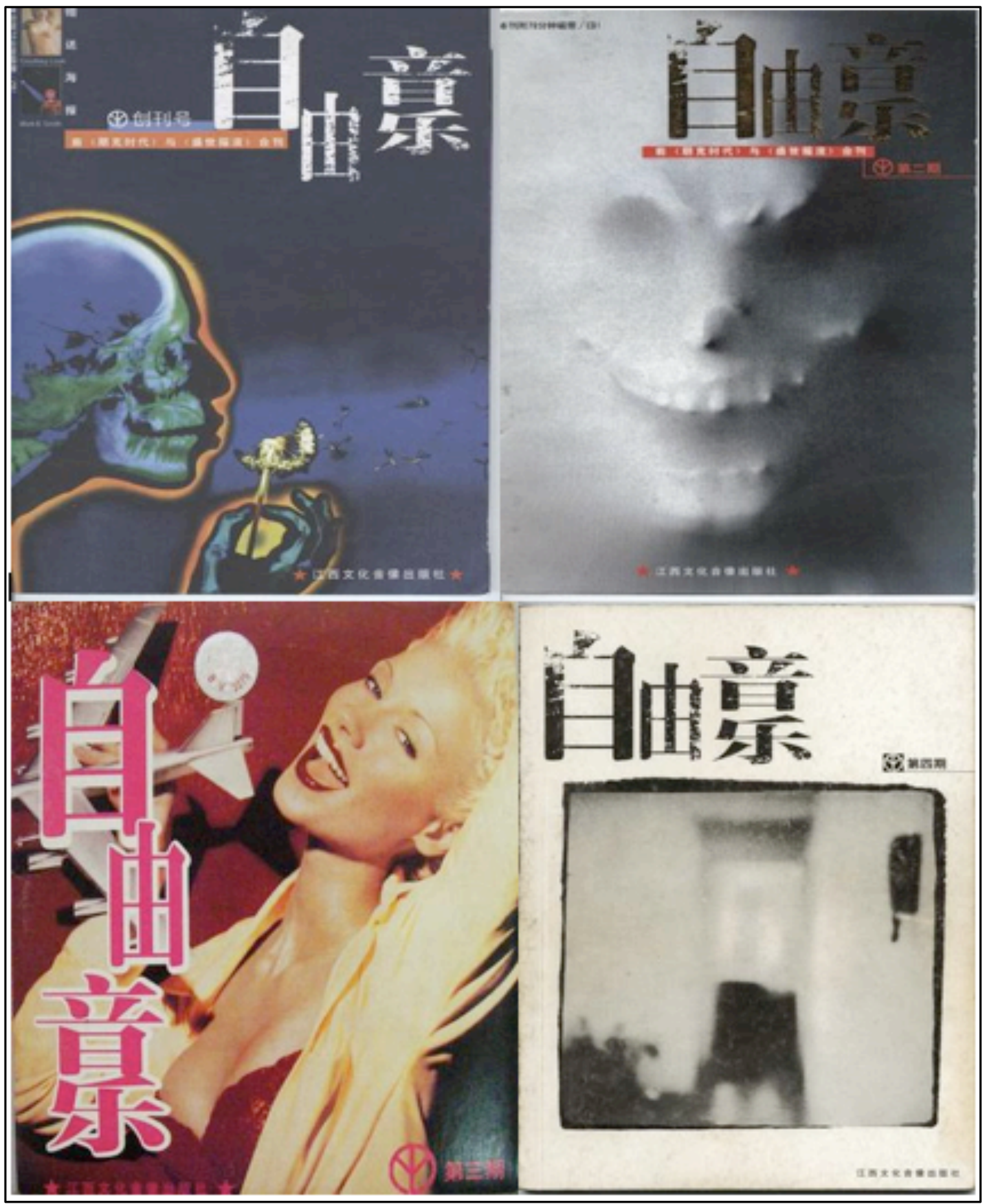

Fig. 3. Free Music: Issue 1, Oct. 1999 (upper left); Issue 2, 2000 (upper right); Issue 3, 2000 (lower left); Issue 4, 2000 (lower right). 


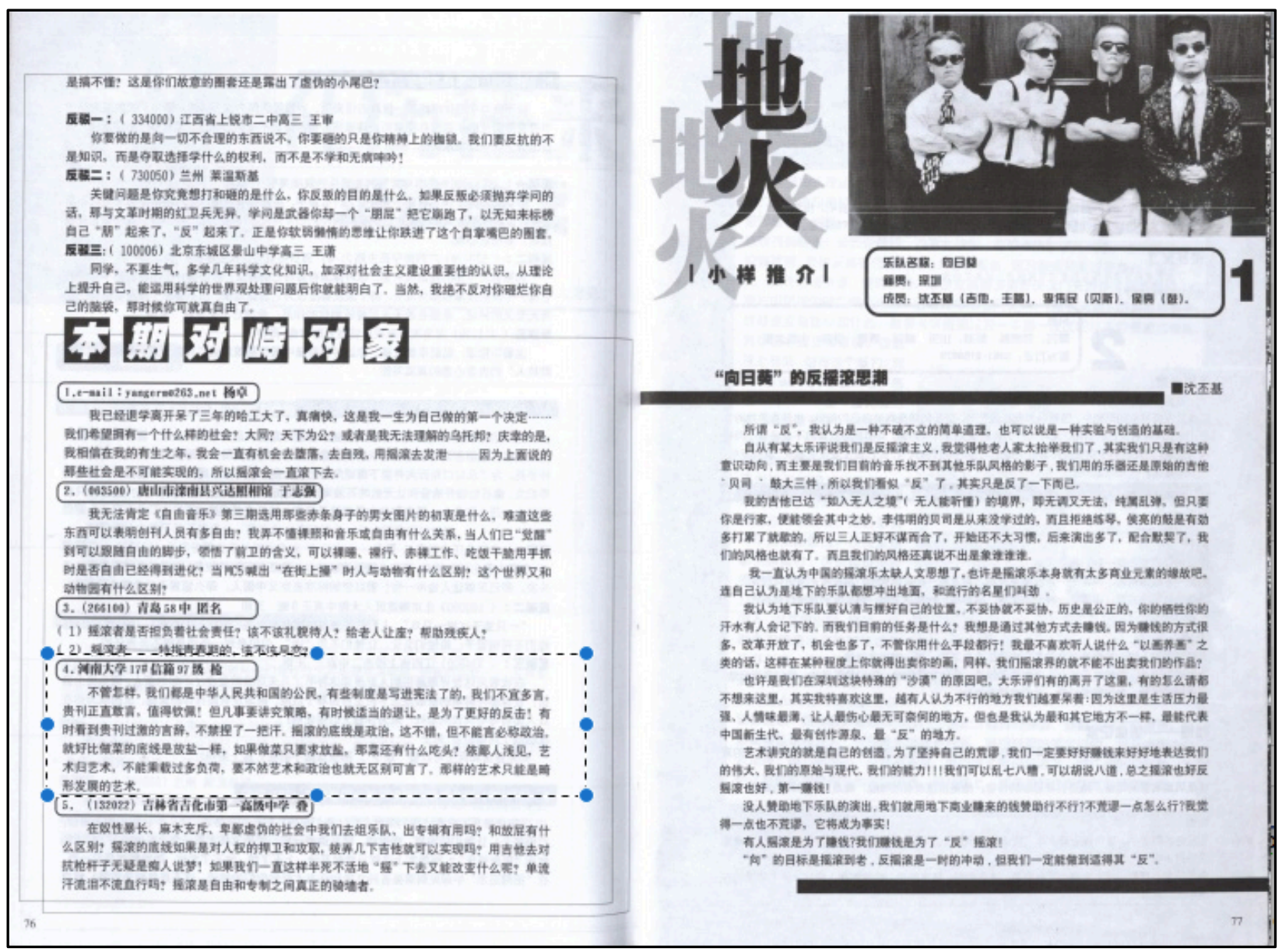

Fig. 4. Reader's letter (highlighted in the blue box) suggesting inappropriate pictures to be removed. Free Music, Issue 4, page 76.

\section{Live Music Festivals and Music Events}

If Free Music nurtured a body of music fans who could appreciate more radical, experimental sound from overseas, then music festivals and concerts proved to be equally crucial in encouraging local musicians to learn and experiment with different styles of music. The 2pi Music Festival (2003-2007), founded by Li Jianhong, and Waterland Kwanyin (2005-2010), founded by Yan Jun, were the two most important platforms for musical exchange between local and international experimental musicians, free improvisers, and sound artists.

\section{2pi Festival in Hangzhou}

The 2pi Music Festival was held annually on the last weekend in November from 2003 until 2007 (see Fig. 5). The first three festivals were held at No. 31 bar and the following two were moved to Loft 49, No. 12 Warehouse (owned by the Common International Cultural Institution). After the first event, all festivals also lasted two days to accommodate the increasing number of musicians invited to perform from other cities and countries.

The fourth festival in 2006 was the most reported and documented, recognized by sound practitioners as a watershed moment in the development of Chinese experimental music and sound art. The word music was removed to better represent an increasingly diverse body of participants, and the event became the 2pi Sound Festival. This year also saw the most performances, compressed into two eight-hour, non-stop shows. ${ }^{10}$ The night after the festival, musicians gathered for four hours to reflect on their performances and the future direction of Chinese experimental music. According to music critic Ding An, "after four years of development, faced with waning creativity and a need for fresh perspective, it became imperative for these musicians to rethink the nature of sound and redefine their identity as artists" (my trans.). 
The last 2pi Festival was held in 2007. In spite of increasing scale and recognition among artists and musicians from abroad, the festival never received any commercial, governmental, organizational, or institutional funding during its five-year run and could afford only rooms and food for its performers-artists and musicians paid for their own transportation. As the only large-scale annual experimental music festival in southern China, the closure of 2 pi was a great loss for both fans and musicians. Li Jianhong and Weiwei (Li's wife and co-director of 2pi), however, displayed a positive attitude when I asked them why they did not continue: "Money was a problem, but we felt that 2pi Festival had done its job in opening up and establishing the scene."
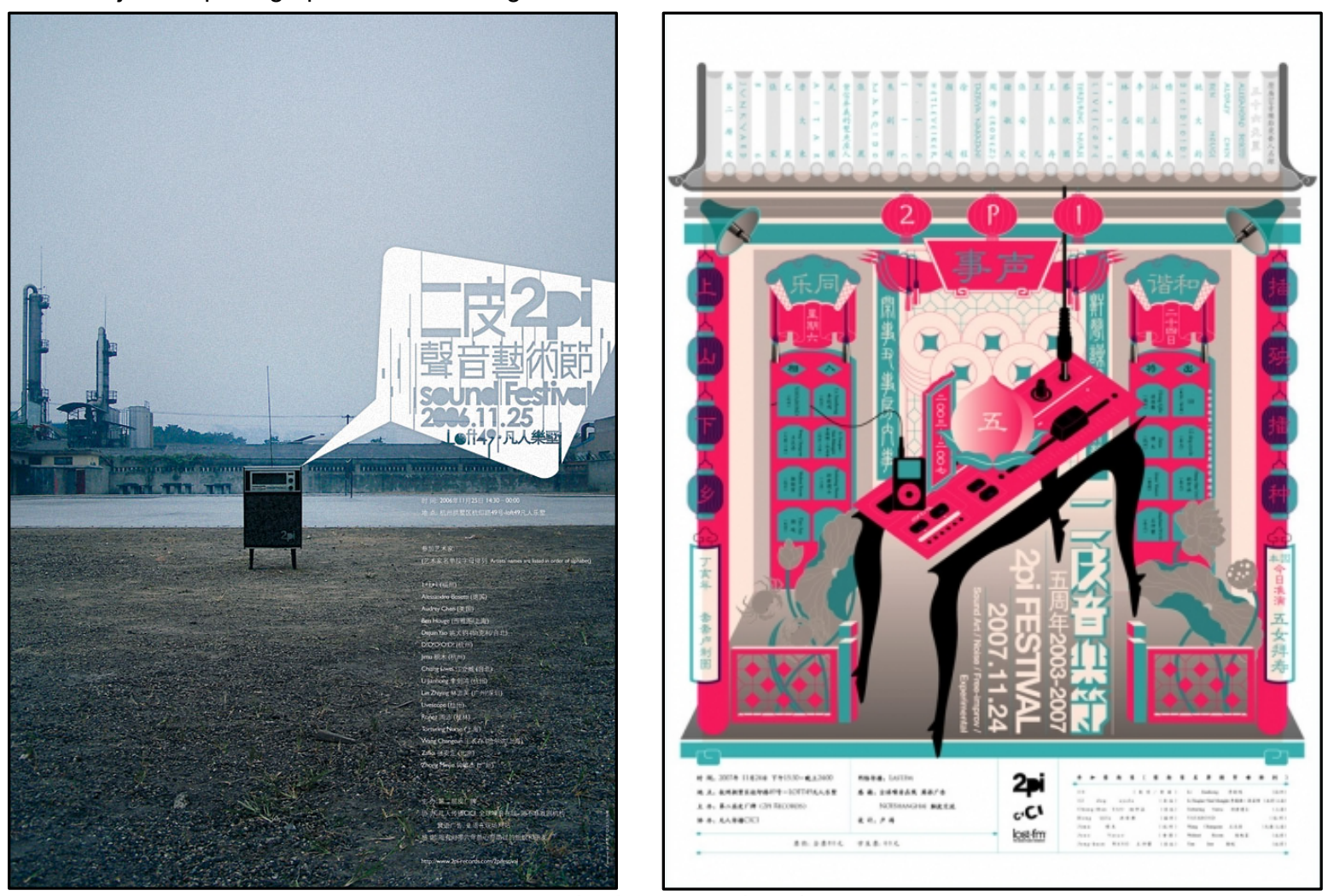

Fig. 5. Posters of the 2006 (left) and 2007 (right) 2pi Sound Festivals.

\section{Waterland Kwanyin in Beijing}

In 2005, Yan Jun, Wu Quan, and the group FM3 initiated Waterland Kwanyin. ${ }^{11}$ This free performance event occurred weekly at the 2 Kolegas Bar (located in a drive-in movie theatre in the Chaoyang District) and featured many forms of avant-garde expression, including spiritual sounds from Buddhist or Taoist rituals, field recording mixes, noise, video art, body performance, and film screenings. In 2008, the schedule was changed to twice a month and the organizers began to charge admission. With its frequent performances and openness to artists of varying abilities, Waterland Kwanyin soon became an important venue for foreign experimental sound artists.

From the first gathering on June 21, 2005 to the last show on January 19, 2010, 167 events were held at 2 Kolegas Bar. Over the course of five years, however, Waterland Kwanyin gradually evolved into a familiar gathering place where local artists and musicians came more to meet old friends than to listen to new sound art. For Yan Jun, this closed sense of community became a serious problem, an obstacle that stifled creative sound production. By the end of 2009, Yan Jun began looking for new performance spaces and in January 2010, right before the Chinese New Year, he terminated the Waterland Kwanyin events.

\section{Conclusion}

In this essay, I describe local improvising music practice in major Chinese cities under the influence of traditional guqin aesthetics, Western rock, and experimental music. Admittedly, there are exceptions. The Free Music Collective of Shanghai is a different paradigm, with half of its members having received fine arts education in Europe and some with domestic art/music training. For this group, free jazz is a more influential factor than rock. Unfortunately, the group has been inactive over the past two years after only two or three public performances. Dickson Dee (Hong 
Kong) is an active organizer and participant of international jazz festivals, including the German-Chinese Jazz Improvising Meet Festival $(2012,2013,2015)$ that he co-organized with Berlin curator Constanze Schliebs. The festival visited multiples cities (Shenzhen, Shanghai, Beijing, and Xiamen) and brought many international jazz musicians to China (Peter Brötzmann, Alexander Von Schlippenbach, Günter Baby Sommer, Michael Schiefel, Aki Takase, the Gebhard Ullmann Clarinet Trio, the Julia Hülsmann Trio, and The Necks). However slow this process may be, such musical exchanges continue to contribute a free jazz sensibility to local improvising music scenes.

During a Mafeisan performance, Weiwei described the process of collective improvisation to me as one where everyone (both musicians and audience) "connects through brainwaves" or "adjusts brainwaves to the same frequency." Despite cultural differences and varied musical backgrounds, Eddie Prévost, Stephen Nachmanovitch, and improvising musicians from China all point to an unmediated connection between individuals-arguably free from existing musical, social, and linguistic structures—that happens while improvising: musicians are "directly" connected to each other, not mediated by scores as in Western classical music (Prévost 359); communication is subtle and immediate, forming a kind of intimacy "that cannot be reached through words or deliberation" (Nachmanovitch 99). Such physiological assessments support the notion that collective improvisation is "instinctual," that there occurs during live performance an entrainment of the participants to the affective atmosphere improvisation created.

What makes China's current improvising practices unique is how they form relationships among musician, audience, and environment. Improvised music is congruent with other creative, everyday practices, not with a staged performance before a paying audience. As in guqin culture, listening to music is a privilege based not on class, but on one's cognitive and sensory state.

\section{Notes}

${ }^{1}$ Cantopop refers to music sung in Cantonese and made primarily in Hong Kong, popular in the Mainland in the 1980s, 1990s, and 2000s.

${ }^{2}$ Liang also describes guqin notation as the most precise and humanistic in the world. The notation is called jianzipu in Chinese and consists of simplified character symbols for both right and left hand movements, providing the positions for different pitches and expressive techniques.

${ }^{3}$ The scholarly class refers to intellectuals who opposed Mao's policies and criticized the Chinese Communist Party during the Cultural Revolution.

${ }^{4}$ This proverb was first coined in the Song Dynasty by the writer and poet $\mathrm{Hu} \mathrm{Zi}$ to describe reckless and wasteful behaviour.

${ }^{5}$ Read the full article for more details on the initial development of Li Jianhong's environment improvisation.

${ }^{6}$ The Tea Rockers Quintet released its first album Ceremony on the Israeli label Ent-T in 2012.

${ }^{7}$ In an email, Yan Jun wrote to me that the performance in Foshan was terrible because the site was more like a night club. The audience was throwing beer bottles and screaming at the musicians. For the performance in Beijing, he said Cui Jian and some other musicians went to the show, but didn't really understand what was going on.

${ }^{8}$ When he first released Free Music, Yang Bo was also one of the editors of another magazine called Music Heaven. He remains a well-known music critic (favoured by musicians and fans of rock, punk, and noise in China) and a respected avant-garde writer. His new novel 眼中的梁木, released in 2008, was brought to my attention during my interview with the Beijing music critic He Xiaoyu.

${ }^{9}$ There is no official record of this censorship. I learned about it secondhand through interviews with Yan Jun and musicians who were fans of the magazine.

${ }^{10}$ Artists included 1+1+1 (Fuzhou), Alessandro Bosetti (Germany), Audrey Chen (U.S.A), Ben Houge (Seattle/Shanghai), Chiang Liwei (Taipei), Dajuin Yao (Taipei), D!O!D!O!D! (Hangzhou), Ji Mu (Hangzhou), Li Jianhong (Hangzhou), Lin Zhiying (Guangzhou/Shenzhen), livescope (Hangzhou), Ronez (Guilin), Torturing Nurse (Shanghai), Tsai Hsinyuan (Taipei), Wang Changcun (Harbin), Wang Fan (Beijing), Zafka (Beijing), and Zhong Minjie (Guangzhou).

${ }^{11}$ See www.subjam.org/file/wk-archives.pdf. 


\section{Works Cited}

Baranovitch, Nimrod. China's New Voices: Popular Music, Ethnicity, Gender, and Politics, 1978-1997. U of California P, 2003.

Ding, An. 第二层皮的第四年一狂欢与自问 [The Fourth Year of 2pi Festival and Self-Reflection], 14 Nov. 2006 , Itrichard.blogbus.com/tag/\%E9\%9F\%B3\%E6\%99\%AF\%7CSoundscape/index_4.html [Page no longer accessible]

FBJ, Fangzhou. Shang de Wudao [Dances on the Boat], 6 Feb. 2006, www.digforfire.net/mambo/index.php?option=com_content\&task=view\&ld=16\&ltemid=42. [Page no longer accessible]

Li, Xiangting. Guqin Zongyi. Renmin UP, 2014.

Liang, Ellen Johnston. "Scholars and Sages: A Study in Chinese Figure Painting." Diss. U of Michigan, 1967.

Liang, Mingyue. Music of the Billion: An Introduction to Chinese Musical Culture. Heinrichshofen, 1985.

Jianhong, Li and Wei, Wei. Personal Interview. 5 August 2010.

Nachmanovitch, Stephen. Free Play: Improvisation in Life and Art. Jeremy P. Tarcher, 1990.

Prévost, Eddie. "The Discourse of a dysfunctional Drummer: Collaborative Dissonances, Improvisation, and Cultural Theory." The Other Side of Nowhere: Jazz, Improvisation, and Communities in Dialogue, edited by Daniel Fischlin and Ajay Heble, Wesleyan UP, 2004, pp. 353-366.

Wang, Jing. "To Make Sounds Inside of A 'Big Can': Proposing a Proper Space for Works of Sound Art." Leonardo, vol. 49, no.1, 2016, pp. 38-47.

---. “Utopian Impulses in China's Sound Culture: The Raying Temple Subculture Collective." Journal of Popular Music Studies, vol. 25, no. 1, 2015, pp. 2-24.

---. "Affective Listening: China's Experimental Music and Sound Art Practice." Journal of Sonic Studies, vol. 2, no. 1, May 2012, journal.sonicstudies.org/cgi/t/text/textidx?c=sonic;sid=228329111373730315c58f57ec4b160c; view=text;idno=m0201a11;rgn=main .

---. “从起点离开徘徊——中国声音工作者及其他” 《音乐研究》，第四期，2011 年 7 月，第 26-35 页。 [Lingering After Crossing the Threshold: On Chinese Sound Workers and Beyond]. Yinyue Yanjiu, vol. 4, 2001, pp. 27-35.

Yan, Jun. Personal Interview. Beijing, 17 July 2009.

Yang, Bo. Free Music, issue 1, Oct. 1999.

Yang, Dian. Qin Xun. Xiling Seal Engraver's Society Publishing House, 2010. 